\title{
Managing Time in a Software Factory: Temporal and Spatial Organization of IS Development Activities
}

\author{
Joe Nandhakumar \\ School of Management, University of Bath, Bath, United Kingdom
}

This article reports an ethnographic study that investigates the ways in which time was experienced and managed in an information systems (IS) development project. The study is based on 6 months of intensive overt participant observation of the development of Executive Information Systems in a large multinational company. Drawing on time geography, this article discusses a social perspective of time and social dynamics of time management in IS development project teams and outlines its implications for formal approaches to time management.

Keywords information systems development, structuration, temporal structuring, time geography, time management, timespace paths

In IS development projects, relatively autonomou s organizational members collaborate to perform complex tasks that require specialized knowledge and expertise. Such project-based teamwork is also a form of working that is common in modern organization s (Dichter, 1991; Hammer, 1997). It appears, however, that IS development projects are poorly served by traditional time management techniques, as evidenced by the frequent late delivery problems in the software industry (Sauer, 1993). Further, the increasing adoption of automated software tools for IS development is also seen as shaping the temporal and spatial organization of activities and management of time in IS development projects (Orlikowski, 1991). This article therefore investigates the ways in which time was

Received 27 June 2000; accepted 21 September 2001.

I thank the participants of the company in which the field study was carried out, for their help and support for this project. I am greatly indebted to Matthew Jones for his stimulating discussions and valuable comments and suggestions for the development of this article.

Address correspondence to Joe Nandhakumar, University of Bath, School of Management, Bath BA2 7AY, UK. E-mail: j.nandhakumar@ bath.ac.uk; web site http://www.bath.ac.uk/ mnsjn experienced and managed in IS development projects and considers its implications for formal approaches to time management.

The study is based on an ethnographic research carried out in a large multinational company involving 6 months of intensive overt participant observation of the development of Executive Information Systems. The analysis draws on social theories, especially on time geography (Carlstein, 1982; Giddens, 1984) as an initial sensitizing device (Walsham, 1993) to structure the interpretation.

The article is structured as follows. The next section contrasts the perspectives on time in IS development with those offered by time geography. The following section outlines the study along with a detailed description of organizational work practices observed during this study. The discussion section draws together our theoretical interpretation s to illustrate some significant features of time management in the company studied. The rich insights gained from this study are finally used to outline some implication s for formal approaches to time management.

\section{PERSPECTIVES ON TIME}

In IS development projects, "time" is mainly perceived as measurable clock time. Thompson (1967) argues that clock time is a feature of capitalism, necessary for the control of the labor process. The approach to time management in mainstream IS development projects (Boehm, 1981; Johnson, 1991) is typically based on techniques of project management such as PERT. Such approaches (if not the actual practices that are based on them) treat IS development work as decomposable into discrete activities, the duration and interactions of which may be reliably estimated. These activities are also seen as being organized into an orderly process, the discrete phases of which are considered to follow a regular sequence. Time management thus focuses on devising an optimal schedule and then allocates the activities to suitably qualified programmers and monitors their completion against the predicted timetable. These approaches to time management 
are therefore typically mechanistic, seeing IS development as essentially programmable and amenable to the precepts of scientific management and thus based on a "software factory" perspective (Johnson, 1991).

From such a perspective, delays and time overruns are usually attributed to inadequate analysis and control of the development process. For example essential activities may have been omitted, estimated completion times may be inaccurate, and timetables may be not adhered to. The solution is therefore seen as ensuring that the data used in the project management system is more accurate and that analysts do not deviate from the plan.

While clock time dominates the perspectives and theories of IS development, in contemporary social theory time is also treated as constitutive of forms of social activities (e.g., Giddens, 1984). To explain this, Giddens (1987) illustrates three interlacing forms of temporality: the durée of day-to-day experience; the life span of the individual; and the longue durée of social institutions. Time in the durée of day-to-day experience is constituted in repetition, that is, time as repetition, temporality as reproduction. The repetition of activities over time leads to the recursive nature of social life, which means that structured properties of the social activities are constantly recreated. The life of the individual, by contrast, is finite, representing the time of the body. Every individual is positioned in the flow of day-to-day life, in the duration of his or her life, and in the longue durée of "institutional time." Thus the third form of temporality, the time of institutions, is both the condition and the outcome of the practices organized in the continuity of daily life. Giddens argues that all activity is situated-it occurs in a specific place, and has a specific duration of time.

Social theorists perceive that the way in which time is organized and managed in human projects depends on the knowledgeable actions of human beings within their particular social context (e.g., Giddens, 1984), rather than the working out of an externally imposed master plan subject to immutable constraints. Social geographers (Hägerstrand, 1975; Carlstein, 1982) have developed a time geography approach to analyze human actions across time-space. This approach looks at the context in which human activities are carried on, tracing how this influences (and is influenced by) the daily movements or paths of human agents and groups. This approach pays particular attention to the source of constraints over human activities deriving from the physical properties of bodies and their social context. Three main types of constraints are identified (Carlstein, 1982):

- "Capability" constraints are limits set by the physical constitution of individuals, such as the indivisibility of the body, which means that people cannot be in two places at once.
- "Coupling" constraints are limits set by the ability of people (and resources) to come together in particular places to interact with one another.

- "Authority" constraints relate to the limits set by social power relationships, such as the permission to perform certain activities.

Typical patterns of movements of individuals can be represented as the repetition of routine activities across days or longer spans of time-space, which are subject to the constraints just described. In order to analyze human activitie s across time and space and the routinized character of daily life, time geographers use dynamic "timespace maps" to represent these daily paths and the overall "boundaries" limiting behavior across time-space provided by these constraints. Figure 1 depicts an example of the day-to-day activities of two parents and their child. One of the parents cannot leave home to work before a certain hour of the day because of the child's dependence on them for food and other needs, such as taking the child to school. The family has no car and hence is faced with capability and coupling constraints in reaching the child's school and the parents' respective places of work. The parents' choice of jobs is restricted by these constraints and other constraints they face in the trajectory of their paths through the day, such as collecting the child from school at a certain time in the afternoon. The parents' paths intersect again at home in the evening, and together they perform other tasks such as cooking and housework.

Individuals' day-to-day activities often lead to successive association with certain locales and individuals. The locales or setting s of interaction s will be spatially bounded, leading to a "regionalization" of time-space. The patterns of interactions within locales is also limited by the overall organization of constraints. Carlstein (1982) illustrates this using a concept of "packing" of "bundles" of timeconsuming activities of different sizes and durations into a group time budget. Human agents, however, are seen not merely as mobile bodies along the time-space trajectories of their daily activities but as intentional beings with purposes referred to as "projects," which they seek to realize through time-demanding activities.

Giddens $(1984,1990)$ has extended these ideas by discussing how individuals carry out the recurrent activities of their day-to-day lives in particular spatial contexts, and through this repetition sustain the structure of social life. Giddens further proposes that individuals should be seen as knowledgeable agents, who actively create (and sustain) the social rules and resources by which they are influenced.

Time geography therefore perceives time and space as inseparable and makes considerable effort to understand social phenomena in terms of a "time-space ecology" (Hägerstrand, 1975). To develop an understanding of how time is managed, we need to start from the way in which 


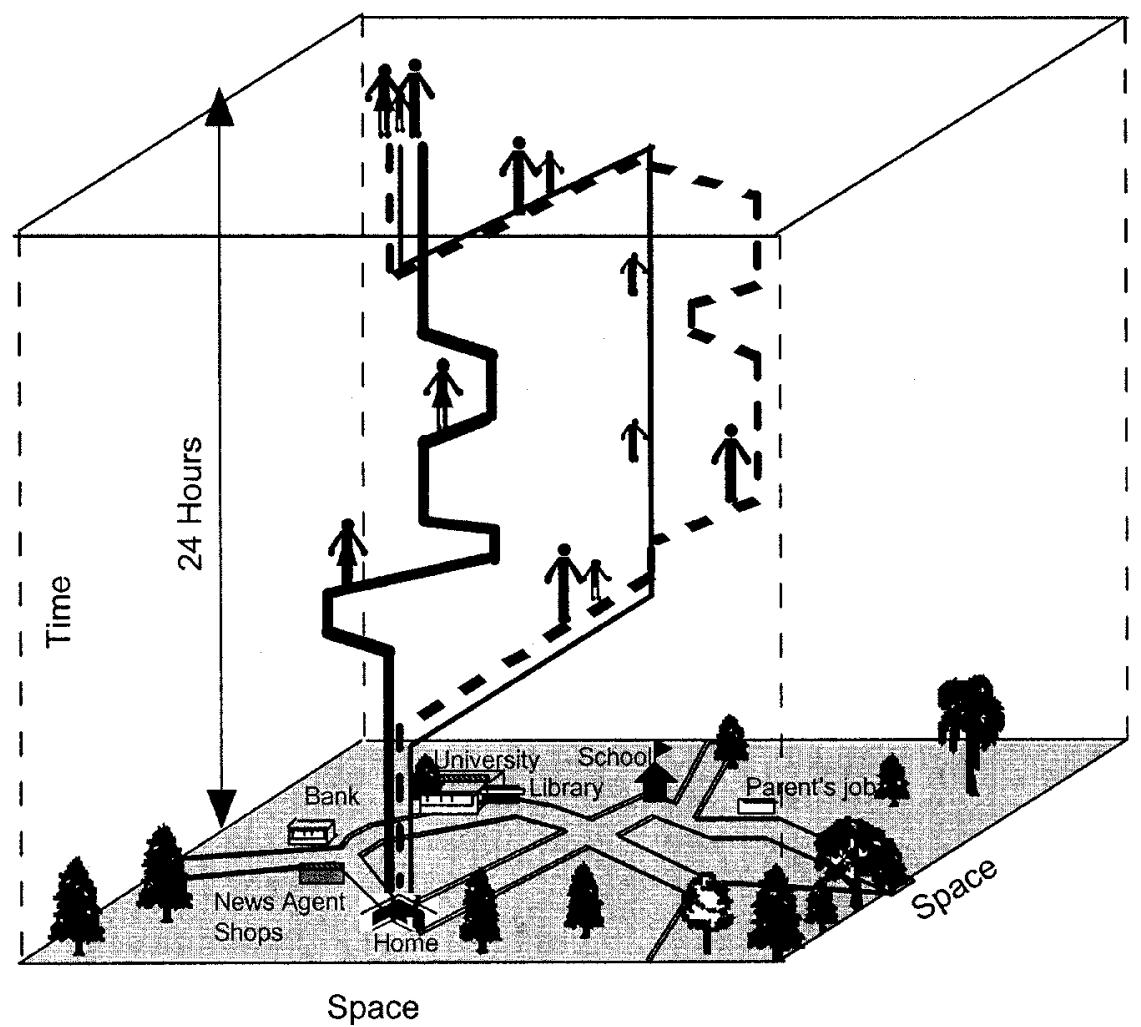

FIG. 1. Time-space paths for two parents and their child over the course of a day.

systems analysts and users organize their work in practice, rather than from how IS development methodologie s and approaches suggest they should work in theory. The extended version of time geography employed by Giddens therefore provides an alternative way of examining the organization of activities in IS development projects to understand the management of time.

\section{RESEARCH STUDY AND RESULTS}

The study was carried out in a Large Manufacturing Company (LMC Europe-a pseudonym) (Nandhakumar \& Jones, 2001). LMC Europe is a volume manufacturer of high-value consumer products, has a multi-billiondollar turnover, and employs over 100,000 staff members throughout Europe. It also has a strong management hierarchy with several layers of senior executives and a divisional structure within the company.

The study is based on 6 months of intensive overt participant observation by the author, who joined as a temporary member (full-time) of a team responsible for the development of the Executive Information Systems, computerbased information systems that provided online access to financial reports for top executives, such as divisional vicepresidents at LMC. The focus of this study was the everyday practices of the team members. During this period a daily log was kept of the activities of the team members (including the researcher's), along with observations and notes of team meetings and discussions.

A detailed case description was written up from the field notes and was used to develop an understanding of the processes observed at LMC (Pettigrew, 1990). In the analysis, extended time geography was adopted as an initial sensitizing device (Walsham, 1993), providing us with concepts to structure our interpretation.

This approach to qualitative data collection and the writing of the description is characteristic of organizational ethnographie s such as van Maanen $(1979,1988)$ and has also increasingly been used to study IS in organization s (e.g., Zuboff, 1988; Prasad, 1993; Nandhakumar \& Jones, 1997; Walsham \& Sahay, 1999). The validity of such research depends on gaining sufficient access to the knowledge and meanings of actors to enable a plausible, credible, and relevant representation of their interpretation s to be generated (Altheide \& Johnson, 1994; Walsham \& Sahay, 1999).

\section{The Context}

The "project team" consisted of a leader, William ${ }^{1}$ (the project manager), three analysts (Mark, Luke, and David), and a trainee (Phil). The researcher (Joe) joined the team 
TABLE 1

Team members and their status in the company

\begin{tabular}{cccccc}
\hline William & Mark & Luke & David & Joe & Phil \\
\hline $\begin{array}{c}\text { Systems manager, } \\
\text { executive systems } \\
\text { project team leader }\end{array}$ & $\begin{array}{c}\text { Senior analyst } \\
\text { (original member } \\
\text { of project team) }\end{array}$ & $\begin{array}{c}\text { Senior analyst } \\
\text { (joined from } \\
\text { finance division) }\end{array}$ & $\begin{array}{c}\text { Senior analyst } \\
\text { (joined from } \\
\text { systems division) }\end{array}$ & $\begin{array}{c}\text { Researcher/ } \\
\text { analyst }\end{array}$ & Trainee \\
\hline
\end{tabular}

as an additional member. Table 1 presents the main actors involved during the period of research. The team was located in a large "open-plan" office along with other finance and systems groups, in the headquarters building of LMC Europe. The project manager's office was also in the same area as the team members' work space, but partitioned off from it. The executives' offices were located in the same building, but in a "penthouse suite" with private access from the car park. The team usually had no contact with executives and complied with the hierarchy at LMC.

The main responsibilities of the team were the development of new executive reports for the executive system (referred to as "projects") and maintenance and support activities, such as modifying and amending reports, fixing hardware- and software-related problems, software upgrades, documentation, and security. Many of these reports provided data relevant to executives' work-for example, key performance indicators such as daily reports on production and inventory levels at each European plant, monthly financial budgets and results, and company news, as well as external data including competitor analysis and financial and general news. New projects were continuously added to the executive system, often in response to requests from vice-presidents who wanted to have all their reports provided through the system.

Personal computer-based software tools were used to develop the system's user interfaces. Many informal design practices, such as a participatory design style involving data providers, had gradually become established within the team, and informal practices established in early projects became the norm for future work. As the system grew larger, with the inclusion of many projects and users (over 100) from different countries in Europe, a mainframe-based system was developed to computerize the shop-floor data entry process for some of the projects. This mainframe-based development work required the analysts to follow the company's formal guideline s and standards for systems analysis, design, and acceptance. In order to legitimize this development work, the team used Information Engineering Facilitie s CASE tools, which had recently been introduced in LMC to speed up IS development process, and followed the Information Engineering methodology.
The project manager was allocated a group budget for the team covering, for example, staff costs, which enabled him to retain a given number of team members. Other items included staff training, non-project-relate d travel expenses, software and hardware purchases for team use, and the hire of external consultants. The purchase of items such as software tools (which automatically generated flow diagrams and program codes) was justified in terms of time savings, based on standardized estimates of time requirements per line of code. Other costs, such as travel or hardware and software purchases, directly relating to a project were generally charged to the commissioning division. The team manager's performance was assessed in terms of timely delivery of projects against this budget. He was also able to bid against other groups in the division for additional funds to cover necessary overtime.

Within the team there were established procedures for estimating time schedules for individual projects (based on standard timings for a wide range of activities, such as upgrading a computer, writing program code, or developing a new project prototype), which were set out in divisional manuals. These, however, were largely regarded as informal guidelines to assist developers. The detailed organization of work activities within the team was generally left to the individual team members, which involved negotiating with colleagues for use of their specific skills, or with other company members, such as data providers, whose collaboration was required for a particular activity. William ensured that team members were present during office hours, unless they were known to be on leave or working elsewhere, and ascertained whether members appeared to be either under- or overloaded. The success of the team in delivering projects to time and budget and the visibility of the system in LMC were used by his superior to assess William's performance.

\section{The Organization of Time in Development Projects}

The description given next is an excerpt from the field notes covering a typical day. This provides an example of data to illustrate the way in which time was experienced and managed in the team at LMC.

Phil continued writing the program for a project relating to personnel while David was on leave, but his work was 
often interrupted by taking phone messages for David. Mark spent most of the day assessing the performance of the new logon procedure and then carried out extensive checks to ensure that the information system for executives was running correctly. He found, by chance, that there were errors in the Daily Production Report and corrected these. He also dealt with a technical problem with one of the executive computers in accessing the external news services which he found to have been caused by a loose cable. Rather than working on the inventory project as planned, Joe had to revise the product development prototype again as the data providers wanted to test the system before their presentation. As a result it was evident that the inventory project would not be ready that week so Joe spent time on catching up with office work, sorting out his computer files, and learning to use the new graphical capabilities of the upgraded software. Because of the restrictions on access to executives' computers Luke was again prevented from making progress with upgrading and spent most of the day talking with another analyst in the executive's division. This was noted by William who had a lengthy discussion with him about the situation. The team members also debated who should carry out the upgrading of the executive computers in an overseas branch which was situated in a holiday resort.

Figure 2 depicts activitie s of team members over a typical 7-day period. Time spent by each team member is indicated by labelled boxes across different activities per day. For example, on day 1 , William spent half his time on project management activities, which involved a meeting with Mark to discuss various projects, and then talked with Joe. He then spent time on administrative and office work. On the same day, Joe spent all morning testing a prototype system for a planned presentation to senior staff from the data provider division. While installing the prototype on the demonstration computer, he encountered several technical problems. Mark, who had been sorting out a problem in report updates on an executive computer, helped Joe to sort them out. Joe had to wait for Mark's expertise before making progress with their own work. Joe then spent the rest of the afternoon designing a routine for showing news on the opening screen. On day 5 (Friday) all team members had to gather in the EIS manager's office for a weekly team meeting at 2 p.m., often suspending their work on other projects.

Differently shaded boxes are used to represent time spent on development activities for each IS development projects (projects 1-4). It indicates that, while it is possible to see projects as moving toward completion in steps or sets of activities in time, these generally consisted of activities from various phases of IS development. Team members' work consisted of a complex mixture of interwoven activities, rather than discrete activities in a neat sequence ordered according to the developer's own priorities in response to various contextual conditions.

\section{ANALYSIS AND DISCUSSION}

\section{Multiple Temporalities}

The evidence from the LMC study indicates that team members' work practices displaye d a complex interdependence. Team members' work was marked by significant changes of pace in which periods of relative inactivity, such as waiting for a colleague to become available to complete some joint task, were matched by intensive efforts as deadlines for projects approached. This would suggest the existence of multiple temporalities, as Kavanagh and Araujo (1995) propose. For example, from the point of view of a particular project, time might typically start off at a leisurely pace, as the first elements of the design were introduced. Time might speed up as interim presentations approached. As evidenced from the excerpt from the field notes just shown, it might then slow down again as other activities, postponed by the immediate deadline, took precedence. Approaching the planned final delivery date, time might accelerate again, or even be suspended as deadlines were extended. As each team member was influenced by different sets of internal (such as aspiration) and external (status, opportunities, changing conditions) constraints, the members were also subject to interlacing forms of temporality. The team members therefore had to organize their time to deal with an intricate mixture of interwoven activities of variable temporal patterns.

Hall and Hall (1990) distinguis h between two temporal patterns: polychronic time and monochronic time. They argue that "a polychronic culture is a culture in which people value, and hence practice, engaging in several activitie s and events at the same time. Monochronic cultures are more linear in that people prefer to be engaged in one thing at a time" (pp. 13-15). Lee (1999) claims that conflicts arise among organizational members on work flow when organizational members operate in a monochronic way while events take place in a polychronic way. $\mathrm{He}$ proposes that such conflicts and bottlenecks can be alleviated by achieving temporal symmetries so that the temporal characteristics of activities are transformed to fit the working patterns, or, on the other hand, the organizational members are trained to deal with activitie s in a polychronic way. As evident from LMC, such conflicts were present when the development team members had to use software tools for much of the development work, which implied a monochronic way. Multiple temporalities of events and activities and interweaving of such activities have made the temporal symmetry (Lee, 1999) difficult to achieve in the LMC context. The bundle of time-consuming activities, however, was "packed," as Carlstein (1982) proposes, into a group time budget.

A fair proportion of team members' activities at LMC were recursive and the time requirements for these were 


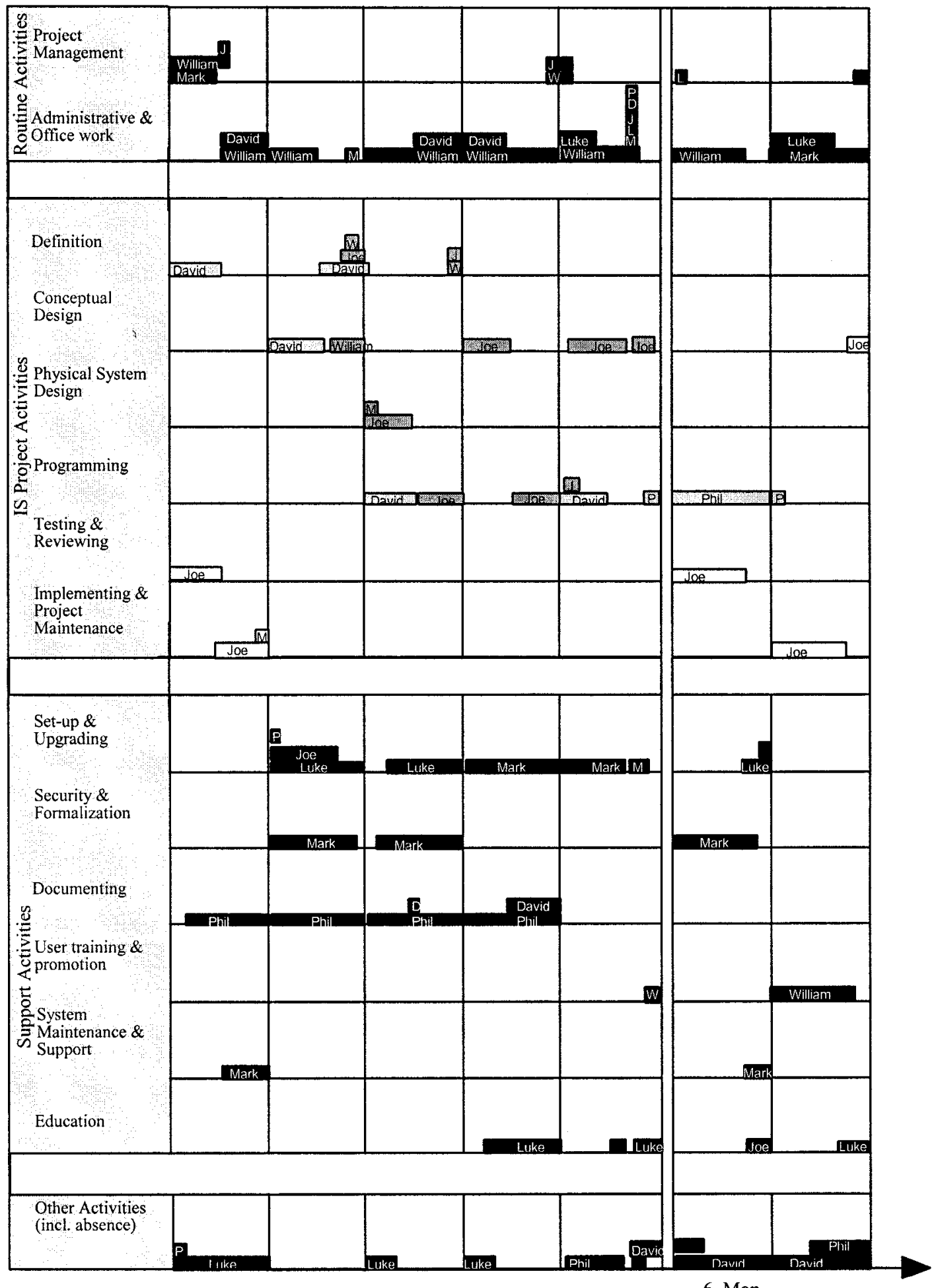

\section{Key: Project 1 Project 2 Project 3 Other Activities $\square$}

FIG. 2. Activities of team members at LMC Europe for a period of 7 days. 
of a routine nature. Expectations of timing and location of these activities, such as project meetings, were institutionalized. Team members also carried out many activities to satisfy their individual or collective needs or aspirations. For example, the team leader sought to find suitable projects and activities for the team and improved report presentations. Further, there were also activities such as resolving problems with executive computers, which were largely unplanned activities but had high priority over other activities because they were requested by executives. The imbalance in power relations also meant that senior members within the team were able to direct the activities of others (cf. Lee, 1999). Organizational norms, conventions, regulations on the use of CASE tools, and commitments made in the past, such as a previous arrangement to upgrade all executive computers, appeared to generate a mixture of activities with multiple temporal forms, reflecting both polychronic time and monochronic time.

\section{Temporal and Spatial Organization of Activities}

The results from the LMC study indicate that the organization of activities within the development team was spatially and temporally differentiated into a number of distinct "locales" such as their office, the foyer, and the restaurant. Each of these was associated with particular types of activity and served as the venue for particular types of routinized social practices, which were often associated with particular times of the day or week. For example, coffee breaks were, by convention, taken at 10 a.m. and 3 p.m. each day in the foyer, lunch was at 12:30 p.m. in the restaurant, and team meetings were held in William's office at 2 p.m. on Fridays. This led to time-space regionalization: The LMC building was the predominant location for "work" activities, and team members were expected to be present there during normal working hours, unless otherwise approved. This time-space regionalization, while constitutive of the team's ongoing social organization, also acted in some ways to constrain team members' activities.

Team members' time management was also influenced by the relatively repetitive nature of many of their work activities. Such routines occurred at several levels. For example, there was the daily updating of reports, and there were weekly team meetings, projects of several weeks duration, annual budgeting rounds, and occasional software upgrades. In each case, prior practice provided norms for subsequent action. For example, although each new project might involve novel challenges, much of the practice would be carried forward from previous experience. New team members were inducted in these practices through formal advice sessions.

Another feature of temporal and spatial organization of activities at LMC was that team members were often simultaneousl y engaged in several different "projects" and types of work, as well as participating in regular formal and informal routines. As discussed already, many different activities were therefore competing for team members' limited time resources and had to be fitted into, and interwoven with, the stream of their other activities. Team members were largely able to switch between different activitie s during the day, as illustrated in Figure 3, which shows the personal time-space path for a single team member on a particular day, switching between different activities: routine; project; support; and social activities. For example, the team member arrives before 8:30 a.m. and engages in routine administrative work, which is interrupted by phone calls, taking messages to a colleague, and collecting printouts from a different office. On his way to the printer, he stops at the systems administration office to discuss the progress with systems security (support activity). Around 9 a.m. he goes out to the foyer for a smoke and to socialize with others. On his return he helps out his colleague on project 2 and then resumes administration work. The vertical path represents time spent on an activity in a particular space and the horizontal path movement in space. Such shifting between activities might be on the basis of personal interest, providing that overall deadlines were met. It was also necessary to be responsive to requests and opportunities for collaboration with colleagues, and to changes in external conditions. Some activities also required coordination and collaboration with other groups such as data providers, or relied on technical resources, the availability and performance of which were often beyond the team members' control. Considerable elements of the team members' work were therefore, of necessity, improvised, and even planned activities were continually changing (Ciborra, 1999).

There were also regular interruption s to team members' work, for example, by phone calls, taking messages for absent colleagues, sorting out technical problems for other team members, or responding to problem reports from executives and their secretaries. While individual interruptions could typically take up only a few minutes, in total they could amount to a substantial diversion from sustained activity. Such interruptions also contributed to breaking up of the day by a series of social "times" (cf. Roy, 1973) such as "smoke time" and "break time." Although these times fragmented the periods available for sustained work, they also contributed to the structuring of social interaction and served as important venues for knowledge sharing, as team members socialized and exchanged ideas (Orr, 1996).

According to time geographers, all activities need to be "packed" into a time budget, which cannot be exceeded. Any time not allocated to particular projects will therefore be filled with other activities since it cannot be stored. 


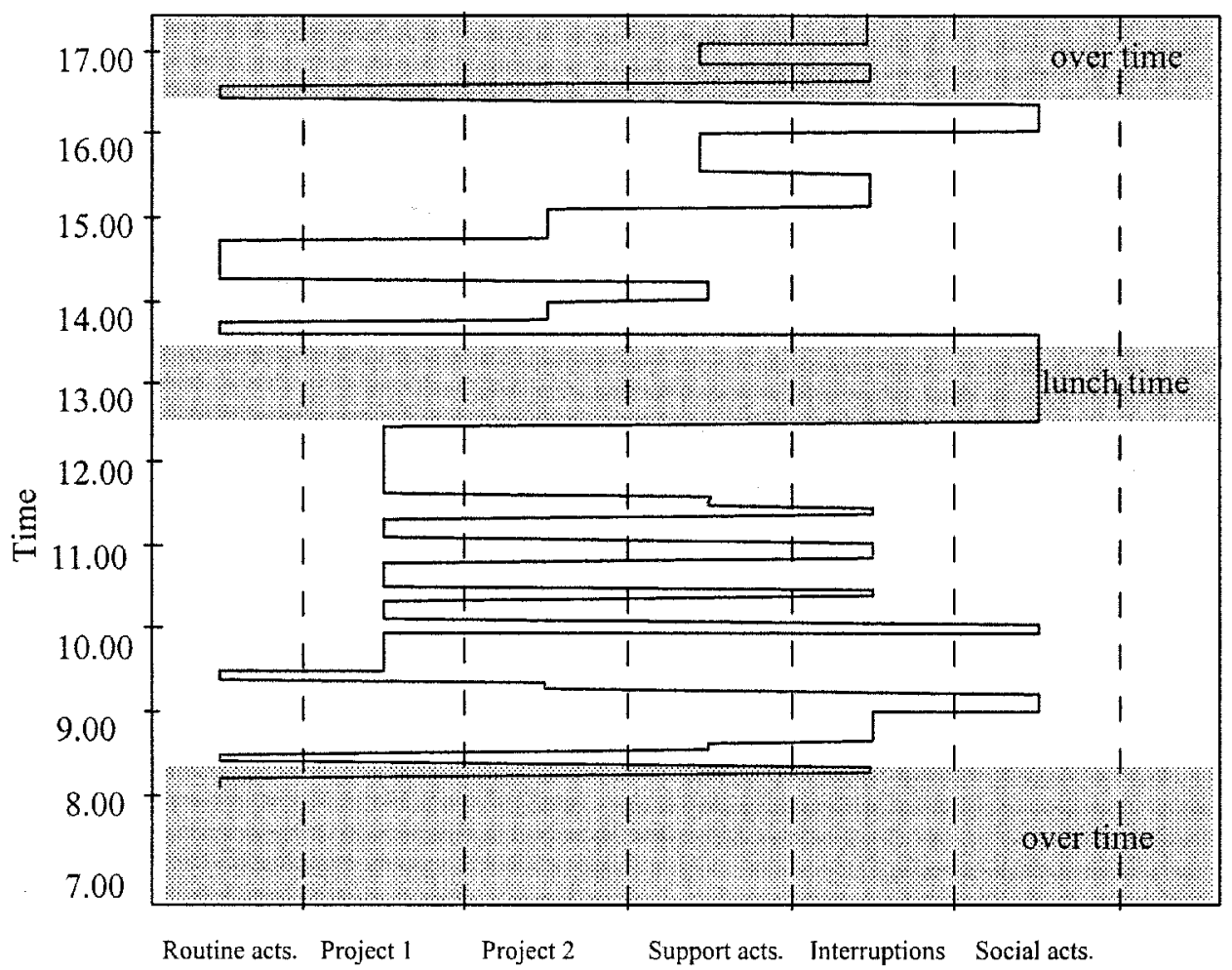

FIG. 3. Personal time-space path for a single team member on a particular day.

For example, team members had to fill in a lot of time with reading and administration while waiting for an executive to be out of his office to upgrade the software on his machine or while waiting for an analyst to become available to obtain help. Team members also had a fair degree of discretion in deciding which activities they could fit into their time budget - for example, deciding to work on maintenance or recommencing another development project. This is not to suggest, however, that temporal and spatial constraints were simply discursive resources that could be unilaterally employed by team members. Rather, there were accepted bounds within which team members' autonomy was permitted, and which were monitored.

\section{Production and Reproduction of Context}

For individual team members their work was subject to multiple, sometimes conflicting, constraints, which shaped the activities in which they engaged. Capability constraints were visible in terms of the skills of particular individu als and the availability of data and equipment. As this shows, capability constraints were closely linked to coupling constraints. Team members frequently had to wait for others with necessary information or expertise to be available in order to make progress with their own work. Authority constraints were in evidence at the time of the team meeting, where all team members had to suspend their work in order to attend. There were also many other social constraints, such as established rules and development practices. For example, norms relating to many of the team's development practices and hierarchical status, such as indirect relationship with executives and participatory design approaches, were not formally documented, but were reproduced as team members were influenced by each other's actions.

Through individuals' daily allocation of time, the structural properties of locales are continuously reproduced. For example, by their regular presence in the office throughout most workdays, members helped to reproduce the attendance norms. Similarly, in accepting LMC's hierarchy and not directly interacting with executive users, the team members also helped to reproduce these constraints. This reproduction was not restricted to activities within the development process. The team members' status within LMC directed the legitimate time-space paths that they could follow - where they could go in the LMC building, where and when they worked or ate, and with whom they interacted. Within the team, members helped to reproduce social norms by, for example, attending team meetings and following their colleagues' established design guidelines. At every instant of action and interaction, however, there were also potential opportunitie s to transform these structural properties. 


\section{Role of IT in Shaping Temporal-Spatial Practices}

The team members' use of new software tools for development practices created a number of different representations of time and space. For example, the analysis phase of data entry system (guided by Information Engineering methodology and CASE tools) was mainly characterized by entity and function analysis, which represented the system as 10 interrelated entities. The software tools helped the team members to construct a reality of an imagined or conceptualized domain in which the members could enact new forms of organizational experience. The design of the data entry system then instantiated this representation, producing new time-space domains. Further, this system also enabled swift delivery of data relevant to executives' work, for example, key performance indicators for each plant. The timely availability of data (through this newly automated data entry procedure) enabled the top executives to develop new views of the organization - for example, by influencing their views on plant performance.

The various software tools used by team members helped to influence structuring of their temporal and spatial practices in various ways. For example, the software allowed access to executives' computers in temporally and spatially remote sites to carryout upgrading of software components. The accessibility of the prototype systems from various computers also enabled each developer to work and interact with others who were temporally present but spatially absent and thereby helped to change the timespace structuring of work practices.

The software tools also provided opportunity for surveillance and control of team members' work practices over time-space. Zuboff (1988) showed from her ethnographic study of computer-based technology in the workplace how managers use IT to retain control and make workers activities transparent. Orlikowski (1991) also provided insights on the effects of detailed surveillance of work practices of the introduction of new forms of information technology, including CASE tools of the sort adopted at LMC, at SCC (a large software consultancy). Her findings suggest that such technologies can indeed serve to extend control of developers' work practices, but at the cost of a loss of "professional" problem-solving abilities, initiative, and creativity. At LMC, however, the team members were ingenious in finding ways to circumvent these control measures provide d by the software tools and used them to their own advantage. For example, often code generation statistics were amended to maintain or enhance the team's status within LMC, and to justify investment in further productivity software. Orlikowski (1991) also noted that attempts to control developers' time are always subject to their willingness to accede to this control, particularly where they possess the technical abilities to disrupt or subvert surveillance.

\section{Control of Work Organization}

The team members' work practices seemed to suggest that there were particular difficulties in controlling this type of work practices, which required greater autonomy, for example, due to task complexity, specialist skill requirements, and ad hoc problem-solvin g capabilities that could not be easily preplanned. This improvisatory character of the team members' work practices is similar to the "bricolage" described by Ciborra (1996) as typical of knowledge work. This reflects the complex interdependence and highly variable nature of the team's work environment.

The relatively low levels of control over team members' time management and the improvisatory character of their work practices do not imply that they were entirely autonomous in their actions. They were subject to various forms of social control: for example, norms promoting collaboration with colleagues, professional design standards, and established routines such as team meetings and shared lunches. Further, there were clearly more overt social and organizational power relationships, for example, in management/employee relations, which significantly shaped team members' actions.

As discussed earlier, team members' work was marked by a flux of interwoven activities and multiple temporalities leading to a highly complex picture of the time experience of team members. Similar to such time experience, space was also perceived by team members as highly differentiated. Individual team members, for example, could be seen to have their working space, informal interaction space, and private space, which might normally be associated with particular physical locales. Further, small variations in physical space might signal significant differences in perceptual space. For example, a part of the work area out of the line of sight of the manager's office might be seen quite differently from one susceptible to direct surveillance. Evidence for this was observed at LMC when the team refused to accept an office reorganization that would have placed William's desk in their midst.

A variety of perceptual spaces may therefore be identified that can be overlaid on the physical space. The most important of these within the LMC context may be seen as "control" space, which represents the degree of perceived visibility to management control. For example the team meetings, taking place in William's office, would be in a zone of high visibility, whereas areas like the foyer, being out of William's direct surveillance, would be relatively weakly controlled. Figure 4 illustrates a team member's daily movements through various control spaces. For example, the team member enters office space around 8:30 a.m. and stays there until around 10 a.m., when he moves to a social space (coffee break), out of direct surveillance by his senior colleagues. The vertical path represents 


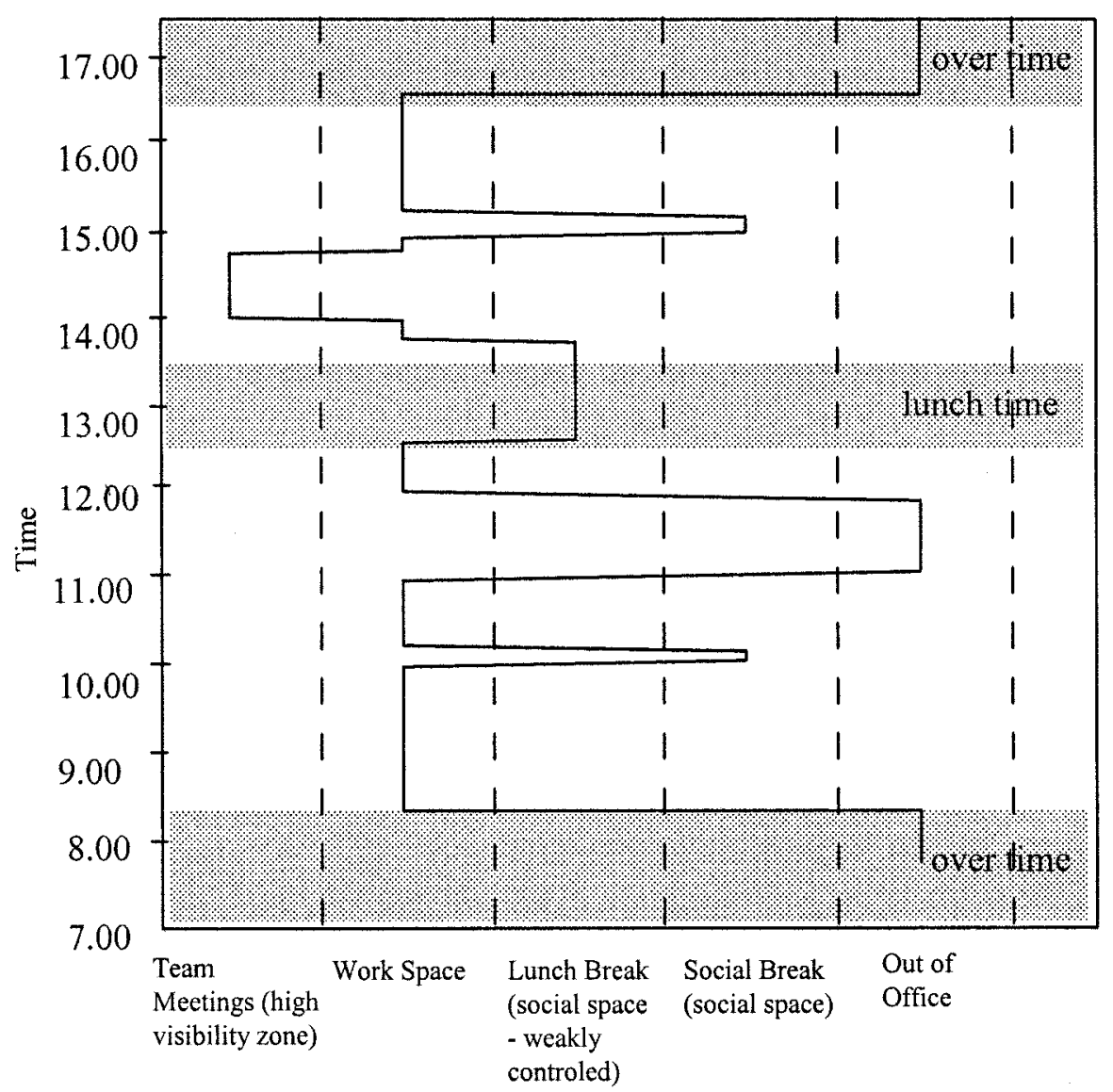

FIG. 4. A team member's daily movements through various control spaces.

time spent on a particular "control space" and the horizontal path movement in space.

Variations in control space may also be affected by indirect means such as through organizational hierarchy, disciplinary mechanisms, and professional standards. For example, Phil was subject to greater control than other team members, as the other analysts as well as William had authority to manage his work. The sanctions on the team members' presence on the executives' office floor and the analysts' belief in their professional status similarly served to control their activities in the absence of direct surveillance.

\section{CONCLUSIONS}

Drawing on time geography, this article offers a broader perspective of time and management of time as experienced by the members of an IS development team in a large multinational company. The picture of time management that emerged from the study is a pervasive characteristic of the constitution of the ongoing social practices rather than a discrete activity that is restricted to a single aspect of temporal structuring.
The management of time was characterized by routines, time-space regionalization, interruptions, personal preference, and mutual negotiation and improvization. Routinized social practices organized time-space into a number of distinct locales, the structural properties of which were continuously reproduced through individuals' daily allocation of time. The time paths of individual analysts involved the interweaving of a variety of different activities during the course of a day. The way in which these were packed into the available time budget was influenced by the individuals' own purposes or preferences, their particular skills and influence in relevant power relationships, and their interactions with coworkers. The daily time budget did not comprise a continuou s period, but was broken up into a series of social times, and further fragmented by unexpected interruptions. Improvisation appeared to be necessitated by the complex interdependence and frequently changing nature of their work practices, indicating a greater degree of variability in time reckoning.

The social organization of time management observed at LMC appeared to facilitate the coordination of the relatively independent individuals with their complex, complementary skill sets. The type of work in which team 
members were engaged also regularly required ad hoc problem-solving skills and abilities such as creativity, which could not be easily preplanned. Moreover, team members were protective of their professional autonomy and aware of the conditions of their surveillance.

Control measures imposed by the software tools were therefore used to team members' advantages, and attempts were made to deceive the monitoring process. The control of developers' time is subject to their willingness to accede to this control, particularly when they possess the technical abilities to subvert surveillance. The team members' use of new software tools for development practices created a number of different representation s of time and space. The software tools helped the team members to construct a reality of an imagined or conceptualized domain in which the members could enact new forms of organizational experience. The various software tools used by team members helped to influence structuring of their temporal and spatial practices in various ways, allowing them to work on different stages of different projects.

The mechanistic model of work, on which formal approaches to IS development and time management are based, would therefore appear to be inadequate to manage team members' practices, and may even produce unintended consequences that reduce the effectiveness of team members' work. This is not to say that they may not be of value as a high-level framework for general planning of large IS development projects - the role for which they were originally intended (Sapolsky, 1972) — but that they are based on an inadequate model of the sort of teamworking environment reported in this article, which is becoming more typical in modern organizations. Social controls, such as norms promoting collaboration with colleagues, professional design practices, and established routines, appeared to be a more significant influence on team members' time management. If we are to make a contribution to improve IS project management, therefore, approaches that acknowledge the socially organized character of work practices in IS development teams and that seek to support them may be more effective than seeking their elimination . The richer understanding of the social dynamics of time management provided by the time geography analysis presented in this article may provide a basis for developing and improving such approaches to time management in IS development projects or in project-based teamworking in general.

\section{NOTE}

1. Throughout this article the names of individuals and their actual job titles have been changed to preserve anonymity.

\section{REFERENCES}

Altheide, D. L., and Johnson, J. M. 1994. Criteria for assessing interpretive validity in qualitative research. In Handbook of qualitative research, eds. N. K. Denzin and Y. S. Lincoln, pp. 485-499. London: Sage.

Boehm, B. W. 1981. Software engineering economics. Englewood Cliffs, NJ: Prentice Hall.

Carlstein, T. 1982. Time resources, society and ecology. London: George Allen \& Unwin.

Ciborra, C. U. 1996. Groupware and teamwork: Invisible aid or technical hindrance? Chichester: John Wiley.

Ciborra, C. U. 1999. Notes on improvisation and time in organizations. Accounting, Management and Information Technologies 9(2): 77-94.

Dichter, S. F. 1991. The organization of the 90s. McKinsey Quarterly 1:145-155.

Giddens, A. 1984. The constitution of society. Cambridge: Polity Press.

Giddens, A. 1987. Social theory and modern sociology. Cambridge: Polity Press.

Giddens, A. 1990. Social theory and modern sociology. Cambridge: Polity Press.

Hägerstrand, T. 1975. Space, time and human conditions. In Dynamic allocation of urban space, ed. A. Karlqvist, pp. 3-14. Farnborough: Saxon House.

Hall, E. T., and Hall, M. R. 1990. Understanding cultural differences. Yarmouth, ME: International Press.

Hammer, M. 1997. Beyond reengineering. London: Harper Collins.

Johnson, J. R. 1991. The software factory: Managing software development and maintenance. London: Butterworth.

Kavanagh, D., and Araujo, L. 1995. Chronigami: Folding and unfolding time. Accounting Management and Information Technology 5(2):103-121.

Lee, H. 1999. Time and information technology: Monochronicity, polychronicity and temporal symmetry. European Journal of Information Systems 8(1):16-26.

Nandhakumar, J., and Jones, M. 1997. Too close for comfort? Distance and engagement in interpretive information systems research. Information Systems Journal 7:109-131.

Nandhakumar, J., and Jones, M. 2001. Accounting for time: Managing time in project-based teamworking. Accounting, Organizations and Society 26(3):193-214.

Orlikowski, W. J. 1991. Integrated information environment or matrix of control? The contradictory implications of information technology. Accounting Management and Information Technology 1(1): 9-42.

Orr, J. E. 1996. Talking about machines: An ethnography of a modern job. Ithaca, NY: Cornell University Press.

Pettigrew, A. M. 1990. Longitudinal field research on change: Theory and practice. Organization Science 1(3):267-292.

Prasad, P. 1993. Symbolic processes in the implementation of technological change: A symbolic interactionist study of work computerization. Academy of Management Journal 36:14001429.

Roy, D. 1973. Banana time: Job satisfaction an informal interaction. In People and organizations, ed. G. Salaman and K. Thompson, pp. 205-222. London: Longman. 
Sapolsky, H. M. 1972. The Polaris system development: Bureaucratic and programmatic success in government. Cambridge, MA: Harvard University Press.

Sauer, C. 1993. Why information systems fail. Henley on Thames: Alfred Waller.

Thompson, E. P. 1967. Time, work discipline and industrial capitalism. Past, Present and Future 38:56-97.

van Maanen, J. 1979. The fact of fiction in organizational ethnography. Administrative Science Quarterly 24:539-550. van Maanen, J. 1988. Tales of the field. Chicago: University of Chicago Press.

Walsham, G. 1993. Interpreting information systems in organizations. Chichester: John Wiley.

Walsham, G., and Sahay, S. 1999. GIS for district-level administration in India: Problems and opportunities. MIS Quarterly 23(1): 39-66.

Zuboff, S. 1988. In the age of the smart machine; The future of work and power. Oxford: Heinemann. 